medRxiv preprint doi: https://doi.org/10.1101/2021.05.16.21257255; this version posted May 21, 2021. The copyright holder for this preprint (which was not certified by peer review) is the author/funder, who has granted medRxiv a license to display the preprint in perpetuity.

It is made available under a CC-BY-NC 4.0 International license.

\title{
Long-term symptoms after SARS-CoV-2 infection in school children: population-based cohort with 6-months follow-up
}

\section{SHORT REPORT}

Thomas Radtke PhD*; Agne Ulyte MD PhD*; Milo A Puhan MD PhD; Susi Kriemler MD Epidemiology, Biostatistics and Prevention Institute (EBPI), University of Zurich,

Hirschengraben 84, 8001 Zürich, Switzerland

* shared first authorship

\section{Corresponding author}

Prof. Susi Kriemler

Epidemiology, Biostatistics and Prevention Institute (EBPI)

University of Zurich

Hirschengraben 84

8001 Zürich, Switzerland

Tel: +41446346320

Email: susi.kriemlerwiget@uzh.ch 
medRxiv preprint doi: https://doi.org/10.1101/2021.05.16.21257255; this version posted May 21, 2021. The copyright holder for this preprint (which was not certified by peer review) is the author/funder, who has granted medRxiv a license to display the preprint in perpetuity.

It is made available under a CC-BY-NC 4.0 International license .

\section{ABSTRACT}

Although long COVID in children exists, it is still unclear to what extent children are affected. The Ciao Corona study is a longitudinal cohort investigating SARS-CoV-2 seroprevalence and clustering of cases among around 2500 children and adolescents (hereafter referred to as children) from 55 randomly selected primary and secondary schools in the canton of Zurich in Switzerland. Between June 2020 and April 2021, we completed three testing phases where we collected venous blood for serological analysis and asked about symptoms with online questionnaires. We compared children who tested positive for SARSCoV-2 antibodies in October/November 2020 with those who tested negative. Children who were seronegative in October/November 2020 and seroconverted or were not retested in March/April 2021 were excluded from the analysis (n=256). In March-May 2021 we assessed the presence of symptoms occurring since October 2020, lasting for at least 4 weeks, and persisting for either $>4$ weeks or $>12$ weeks. Overall, 1355 of 2503 children with a serology result in October/November 2020 and follow up questionnaire in March-May 2021 were included. Among seropositive and seronegative 6- to 16-year-old children, $9 \%$ versus $10 \%$ reported at least one symptom beyond 4 weeks, and $4 \%$ versus $2 \%$ at least one symptom beyond 12 weeks. None of the seropositive children reported hospitalization after October 2020. This study suggests a low prevalence of symptoms compatible with long COVID in a randomly selected population-based cohort of children followed over 6 months after serological testing.

\section{INTRODUCTION}

Children can suffer from SARS-CoV-2 postviral syndromes, but it is yet unclear to what extent children are affected by long COVID, herein defined as symptoms that continue for more than 12 weeks after SARS-CoV-2 infection and are not explained by an alternative diagnosis. ${ }^{1}$ Current evidence is predominantly limited to selective - mostly clinical - 
populations without control groups ${ }^{2-5}$, which do not allow estimating the overall prevalence and burden in a general pediatric population. In this study, we compared long COVID compatible symptoms in children with 6-months follow-up according to their SARS-CoV-2 serology.

\section{METHODS}

The Ciao Corona study is a longitudinal cohort investigating SARS-CoV-2 seroprevalence and clustering of cases among around 2500 children from 55 randomly selected primary and secondary schools in the canton of Zurich (about 1.5 million inhabitants) in Switzerland (study design described elsewhere $^{6}$ ). Between June 2020 and April 2021, we completed three testing phases where we collected venous blood for serological analysis and asked about symptoms with online questionnaires. For serological analysis, we used the ABCORA 2.0 test. $^{6}$

In this analysis, we compared children who tested positive for SARS-CoV-2 antibodies in October/November 2020 with those who tested negative. Children who were seronegative in October/November 2020 and seroconverted or were not retested in March/April 2021 were excluded from the analysis ( $n=256)$. In March-May 2021 we assessed the presence of symptoms occurring since October 2020 and lasting for at least 4 weeks ${ }^{3}$, and persisting for either $>4$ weeks or $>12$ weeks.

Descriptive analysis was performed with $\mathrm{R}$ version 4.0.3. The Ethics Committee of the Canton of Zurich, Switzerland (2020-01336) approved the study and parents/legal guardians provided written informed consent.

\section{RESULTS}


Overall, 1355 of 2503 children with a serology result in October/November 2020 and follow up questionnaire in March/April 2021 were included. Participant characteristics, symptoms and self-rated health are summarized in the Table. Among seropositive and seronegative children, 9.2\% (10/109) versus 9.7\% (121/1246) reported at least one symptom beyond 4 weeks, and 3.7\% (4/109) versus $2.2 \%(28 / 1246)$ at least one symptom beyond 12 weeks (Table). None of the seropositive children reported hospitalization after October 2020. The distribution of pre-existing chronic health conditions among seropositive $(n=109)$ and seronegative children $(\mathrm{n}=1246)$ is given in Supplemental Table S1. Participant characteristics, symptoms and self-rated health for a subpopulation of seropositive $(n=89)$ and seronegative children ( $\mathrm{n}=891)$ without chronic health conditions is shown in Table S2. 
Table Participant characteristics, symptoms and self-rated health among seropositive and seronegative children.

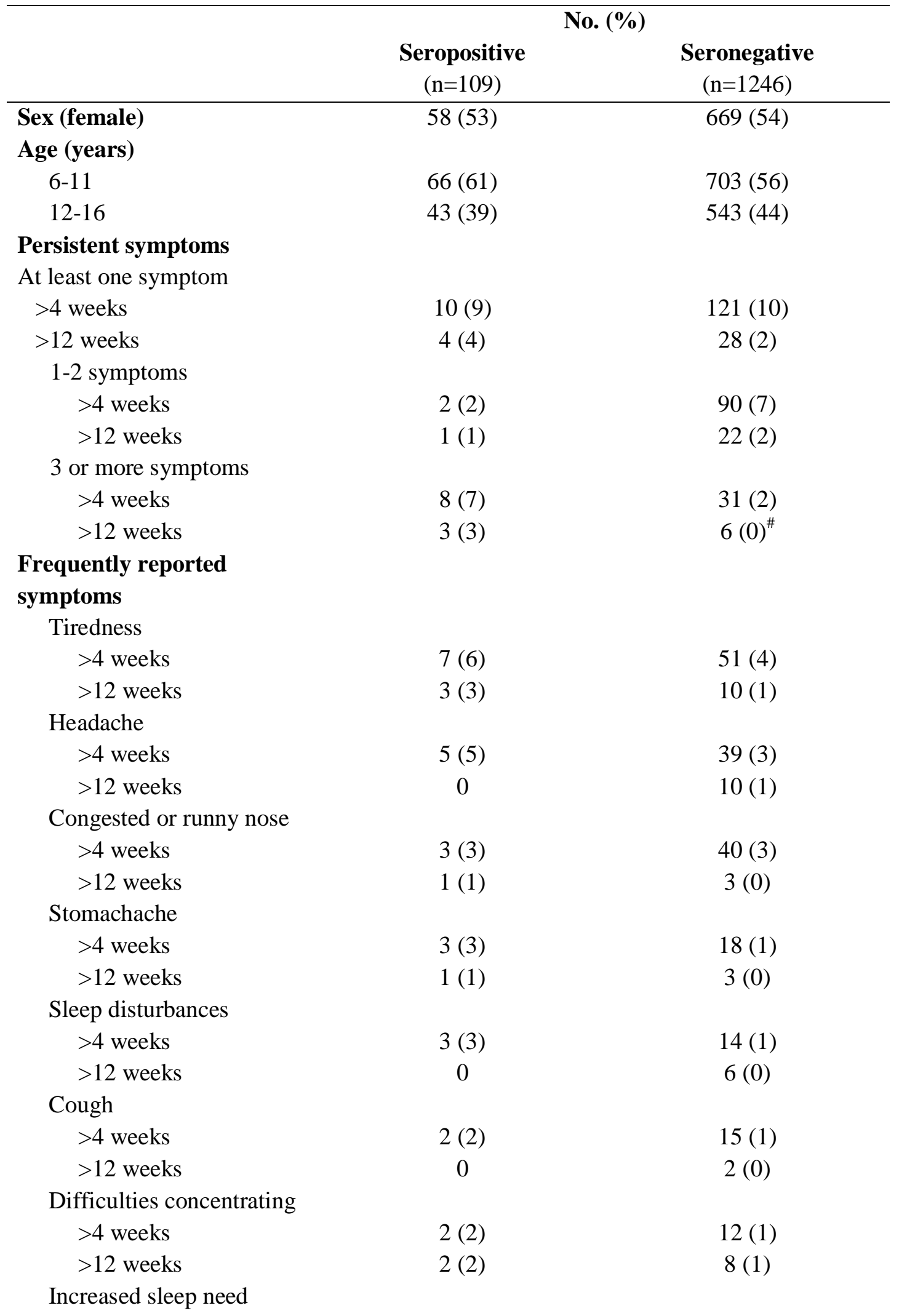


$>4$ weeks

$>12$ weeks

Self-rated health

Excellent

Good

Fair

Poor
$2(2)$
$5(0)$

$0(0)$

$497(41)$

$680(55)$

$48(4)$

$2(0)$

Among seropositive and seronegative children, $3(3 \%)$ and $22(2 \%)$ reported at least one symptom for $>12$ weeks and ongoing. The item self-rated health from the Health Behaviour in School-Aged Children (HBSC) - Survey Instrument Would you say your health is...? assesses perceived health status of a child/adolescent and includes four response categories labelled as "excellent", "good", "fair", "poor". Self-rated health was not reported for 3 seropositive and 19 seronegative children. ${ }^{\#} 6 / 1246$ (0.482\%).

\section{DISCUSSION}

This study suggests a low prevalence of symptoms compatible with long COVID in a randomly selected population-based cohort of children followed over 6 months after serological testing. Seropositive children, with mostly asymptomatic SARS-CoV-2 infection, did not report these symptoms lasting for longer than 12 weeks more frequently than seronegative children.

While even severe forms of long COVID in children exist ${ }^{4}$, the estimates on prevalence range from $95 \%$ of children reporting symptoms within 8 months of follow-up ${ }^{3}$, to $1.8 \%$ of schoolchildren at 2 months in a large surveillance study ${ }^{2}$ or to full recovery in all children with predominantly mild disease ${ }^{5}$. Initial SARS-CoV-2 infection severity, different methodological approaches (clinical assessment versus self-report), definition of cases (diagnosed versus suspected cases), variable follow-up times, and prevalence of pre-existing chronic health conditions likely contribute to the variability of long COVID reported in children. Longitudinal data on large population-based samples are needed to better understand its potential impact on health-related quality of life and activities in daily living including going to school.

Strengths of our study include the large, representative, randomly selected sample of school children and inclusion of a population-based seronegative control group that could be 
ensured thanks to the longitudinal design. Limitations include the relatively small number of seropositive children, possible misclassification of some false seropositive or seronegative children, potential recall bias, parental report of child's symptoms, and lack of information on symptom severity.

\section{FUNDING}

This study is part of the Corona Immunitas research network, coordinated by the Swiss School of Public Health (SSPH+), and funded by fundraising of SSPH+ that includes funds of the Swiss Federal Office of Public Health and private funders (ethical guidelines for funding stated by SSPH+ were respected), by funds of the cantons of Switzerland (Vaud, Zurich, and Basel), and by institutional funds of the universities. Additional funding, specific to this study, was available from the University of Zurich Foundation. The funder/sponsor did not have any role in the design and conduct of the study; collection, management, analysis, and interpretation of the data; preparation, review, or approval of the manuscript; and decision to submit the manuscript for publication. All authors had full access to all data analysis outputs (reports and tables) and take responsibility for their integrity and accuracy.

\section{CONFLICT OF INTEREST}

None 
medRxiv preprint doi: https://doi.org/10.1101/2021.05.16.21257255; this version posted May 21, 2021. The copyright holder for this preprint

(which was not certified by peer review) is the author/funder, who has granted medRxiv a license to display the preprint in perpetuity.

It is made available under a CC-BY-NC 4.0 International license .

\section{REFERENCES}

1. COVID-19 rapid guideline: managing the long-term effects of COVID-19 | Guidance |

NICE. Accessed May 12, 2021. https://www.nice.org.uk/guidance/NG188

2. Molteni E, Sudre CH, Canas LS, et al. Illness duration and symptom profile in a large

cohort of symptomatic UK school-aged children tested for SARS-CoV-2. medRxiv. Published online May 8, 2021:2021.05.05.21256649. doi:10.1101/2021.05.05.21256649

3. Buonsenso D, Pujol FE, Munblit D, et al. Clinical Characteristics, Activity Levels and Mental Health Problems in Children with Long COVID: A Survey of 510 Children. Published online March 9, 2021. doi:10.20944/preprints202103.0271.v1

4. Buonsenso D, Munblit D, Rose CD, et al. Preliminary evidence on long COVID in children. Acta Paediatrica. Online ahead of print. doi:https://doi.org/10.1111/apa.15870

5. Say D, Crawford N, McNab S, et al. Post-acute COVID-19 outcomes in children with mild and asymptomatic disease. The Lancet Child \& Adolescent Health. 2021;0(0).

doi:10.1016/S2352-4642(21)00124-3

6. Ulyte A, Radtke T, Abela IA, et al. Clustering and longitudinal change in SARS-CoV2 seroprevalence in school children in the canton of Zurich, Switzerland: prospective cohort study of 55 schools. BMJ. 2021;372:n616. doi:10.1136/bmj.n616 
medRxiv preprint doi: https://doi.org/10.1101/2021.05.16.21257255; this version posted May 21, 2021. The copyright holder for this preprint (which was not certified by peer review) is the author/funder, who has granted medRxiv a license to display the preprint in perpetuity.

$$
\text { It is made available under a CC-BY-NC } 4.0 \text { International license. }
$$

